Ann. Zootech., I980, 29 (3), 339-36r.

\title{
Influence des traitements technologiques sur l'utilisation des protéines de la féverole par le veau préruminant
}

\author{
R. TOULLEC, J. Y. COROLIER, P. PATUREAU-MIRAND(1), \\ J. P. MELCION $\left({ }^{2}\right)$, J. P. PRUGNAUD( ${ }^{(1)}$, Paulette VALDEBOUZF $\left({ }^{\mathbf{2}}\right)$, \\ J. DELORT-LAVAL, $\left({ }^{2}\right)$ et Juta CERNING-BEROARD $\left(^{3}\right)$ \\ Station de Recherches Zootechniques, \\ Centre de Recherches de Rennes, I.N.R.A., \\ 35042 Rennes Cédex (France). \\ (1) Laboratoive d'Étude du Métabolisme Azoté, \\ Centre de Recherches de Clermont-Ferrand, I.N.R.A., \\ Theix, 63IIo Beaumont (France). \\ (2) Laboratoive de Technologie des Aliments des Animaux, \\ Centre de Recherches de Nantes, I.N.R.A., \\ Chemin de la Géraudière, 44072 Nantes Cédex (France). \\ (') Laboratoive de Biochimie et Technologie Laitières, \\ Centre national de Recherches Zootechniques, I.N.R.A., \\ $7835^{\circ}$ Jouy-en-Josas (France).
}

\section{Résumé}

L'utilisation de 5 produits (tabl. I), préparés à partir de féverole décortiquée (féveroles crue, floconnée, infranisée ou eririchies en protéines soit par turboséparation, soit par fermentation par Saccharomyces carlbergensis), a été étudiée chez le veau préruminant.

La digestibilité d'aliments d'allaitement (tabl. 2) dans lesquels ces prođuits apportaient 4I $^{\mathrm{I}}$ (féveroles crue, floconnée et infranisée), 50 (féverole turboséparée) ou 75 (féverole fermentée) p. I oo des protéines, a été mesurée dans une série d'expériences de bilans. Le reste des protéines était fourni par de la poudre de lactosérum (aliment Féverole fermentée) ou de lait écrémé (autres aliments) et des acides aminés de synthèse. La féverole fermentée a été comparée à un tourteau de soja fermenté par la même levure.

L'appétit des animaux n'a été satisfaisant qu'avec les aliments Féverole et Soja fermentés (tab1. 4). La digestibilité apparente de l'azote de la féverole crue a été faible $(0,72) ;$ le floconnage, la turboséparation et la fermentation ont permis de l'accroître dans des proportions très voisines (jusqu'à respectivement $0,79-0,78$ et 0,79 au delà de l'âge d'un mois) mais c'est l'infranisation qui a eu l'effet le plus favorable $(0,83)$. Le soja fermenté a eu la même digestibilité $(0,79)$ que la féverole correspondante.

L'examen de la composition en acides amitiés des fèces indique qu'elles ne renferment qu'une faible proportion de protéines alimentaires (tabl. 5 et fig. I); cela résulte principalement de la digestion microbienne dans le gros intestin, puisque les protéines alimentaires semblent se trouver en quantités non négligeakles à la fin de l'iléon, au moins pour les aliments Féveroles crue, floconnée et infranisée. La part des protéines alimentaires paraît plus faible à ce niveau avec la féverole infranisée; l'augmentation dela digestibilité apparente de l'azote dela féverole provoquée par l'infranisation serait donc due au moins en partie à une amélioration de sa digestibilité réelle. 
L'influence du remplacement d'une partie des protéines du lait par celles des féveroles crue, infranisée ou fermentée a été étudiée au cours d'une expérience d'engraissement. Quatre aliments d'allaitement ont été utilisés (tabl. 3). Dans l'aliment Témoin, les protéines provenaient exclusivement de la poudre de lait écrémé; dans les 3 autres aliments, les féveroles étudiées apportaient I4 p. Ioo des protéines digestibles, le reste étant fourni par de la poudre de lait écrémé et des acides aminés đe synthèse. Chacun de ces aliments a été distribué à I 2 veaux mâles de race Frisonne, entre les âges d'environ I 5 et I I 3 j.

Le gain de poids vif, l'efficacité alimentaire et le renđement commercial ont été significativement moins satisfaisants avec l'aliment Féverole crue qu'avec l'aliment Témoin (tabl. 9). I'infranisation et surtout la fermentation ont permis de limiter, mais non de supprimer, l'altération de la croissance et de l'efficacité alimentaire.

Aucun des traitements étudiés ne paraît fournir de produit susceptible d'apporter une part très importante des protéines des aliments d'allaitement pour veaux.

\section{Introduction}

L'utilisation des produits issus de la féverole par le veau préruminant a été très peu étudiée. Des résultats défavorables ont été obtenus en incorporant dans des laits de remplacement de la farine (TERRoINe, I93I) ou un concentrat protéique de féverole préparé soit par extraction alcaline (GUIr.oTEAU et al., I977), soit par voie physique (WITTENBERG et INGALLS, I979). En revanche, DUTHJE et al. (1974) ont observé une croissance satisfaisante chez le veau et l'agneau en remplaçant environ $40 \mathrm{p}$. Ioo des protéines du lait par celles d'un isolat de féverole.

La graine de féverole contient des substances indésirables, notamment des hémagglutinines, des facteurs antitrypsiques (MARQUARDT et al., I975; VALDEBOUze et al., I980), des $\alpha$ galactosides (Cerninc, SAPosnik et Guilbot, I975) et des tannins (TANGUY et MARTIN, I973). Les traitements technologiques permettant d'éliminer tout ou partie de ces substances devraient donc améliorer l'utilisation de la féverole par les animaux. Ainsi, le décorticage et le chauffage entraînent une augmentation de la digestibilité des protéines chez le porc et le rat (VERMOREL, I972; IE DIVIDICH, I973). Le but de ce travail était d'étudier l'effet de traitements (infranisation, floconnage, turboséparation et fermentation) plus économiques que la préparation d'isolats protéiques, sur la digestibilité et la croissance chez le veau préruminant. La composition en acides aminés et en hexosamines des fèces et des digesta iléaux, ainsi que les teneurs en acides aminés libres du sang, ont également été déterminées, dans le but d'interpréter les différences observées.

\section{Matériel et méthodes}

\section{Produits étudiés (tabl. I)}

Le même lot de graines, de variété Ascott, a servi à l'ensemble des essais. Les graines ont toujours été décortiquées avant l'application des traitements étudiés, de manière à éliminer la cellulose et les tannins qui sont localisés principalement dans la coque (MarquardT et al., I975; TANGUY et Martin, I973). Trois types de traitements ont été étudiés : le chauffage par floconnage ou infra- 
UTILISATION DES PROTÉTNES PAR LE VEAU

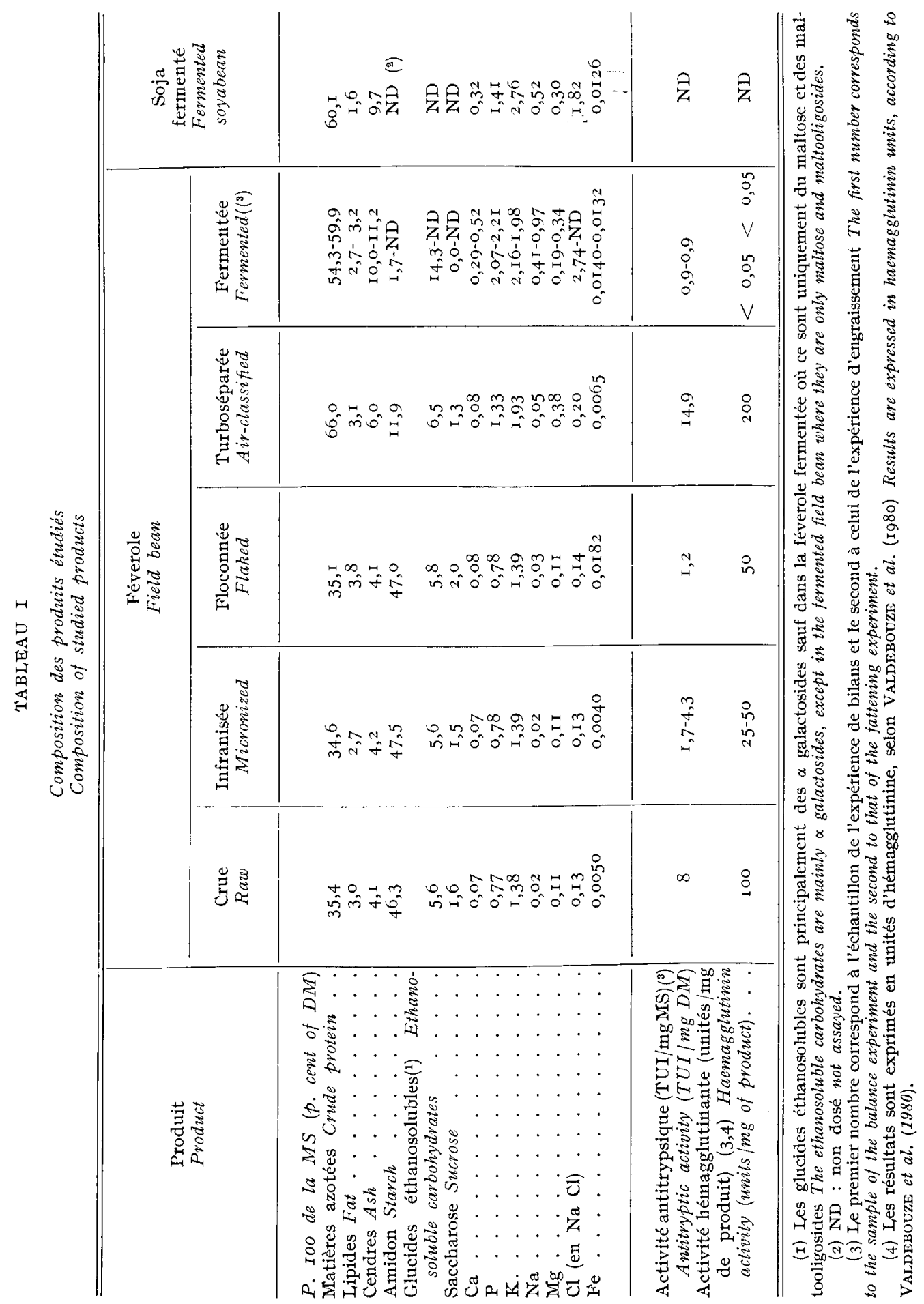


nisation suivis d'un applatissage, la concentration des protéines par turboséparation et la fermentation par Saccharomyces carlbergensis.

Les traitements thermiques ont été décrits par ailleurs (MELcron et VALDEBOUZE, I977). Deux séries différentes d'infranisation ont été réalisées dont la première pour une expérience de bilans et la seconde pour un essai d'engraissement. Le floconnage et la première infranisation ont entraîné l'élimination de la majeure partie de l'activité antitrypsique et d'une part importante de l'activité hémagglutinante. La seconde infranisation, plus brève, a été moins efficace que la première.

La turboséparation a permis d'obtenir un produit enrichi en protéines et appauvri en amidon, par rapport à la féverole décortiquée initiale; mais la teneur en $\alpha$ galactosides a légèrement augmenté et celles en activités antitrypsique et hémagglutinante se sont accrues dans des proportions voisines de celle en protéines.

I a fermentation a été précédée d'un empesage thermique et de traitements enzymatiques par une $\alpha$ amylase et une amyloglucosidase. Elle s'est traduite par un enrichissement en protéines, aux dépens de l'amidon, du saccharose et des $\alpha$ galactosides qui ont pratiquement disparu; les activités antitrypsique et hémagglutinante ont été fortement réduites. Deux séries différentes de fermentation ont également été réalisées, la première pour une expérience de bilans et la seconđe pour l'essai d'engraissement. La digestibilité de la féverole fermentée a été mesurée en même temps que celle d'un tourteau de soja fermenté par la même levure.

\section{Expériences de Bilans}

\section{Essai I: Utilisation digestive des féveroles crue, floconnée et infranisée}

Un essai préalable ayant indiqué qu'au-delà de 30 p. Ioo d'incorporation de féverole crue dans l'aliment d'allaitement, les veaux refusaient une part très importante de leur ration, il a été nécessaire de se limiter à un remplacement partiel des protéines du lait (4I p. Ioo) dans les aliments expérimentaux (tab1. 2).

Six veaux mâles de race Frisonne ont été achetés à l'âge d'environ 8 jours. Ils ont d'abord reçu pendant 36 jours un lait de remplacement dont les protéines provenaient exclusivement du lait et auquel ont été substitués en 4 jours les aliments expérimentaux. Chacun de ces aliments a été distribué simultanément à 2 veaux. Les mesures ont été effectutées en 3 périodes dont la première a commencé Io jours après la fin de la transition. Chaque période de mesures a duré 2 semaines au cours desquelles les fèces et 1'urine ont été collectées et échantillonnées tous les jours, sauf le samedi et le dimanche. A l'issue de la première et de la seconde périodes, les aliments ont été intervertis en 4 jours, de telle sorte que chaque veau reçoive chacun d'entre eux dans un ordre différent. L ses 2 dernières périodes ont commencé 3 jours après la fin des transitions.

De plus, pour étudier la composition des digesta iléaux, 4 veaux mâles de race Frisonne ont été munis d'une canule réentrante placée peu avant la valvule iléo-caecale (BESLE, LASSALAS et THIVEND, I980). Les aliments Féveroles crue, infranisée et floconnée ont été distribués respectivement à $I, 2$ et I veaux.

\section{Essai 2: Utilisation digestive de la téverole turboséparée}

Un essai antérieur (ToulLEC, résultats non publiés) ayant montré qu'un aliment dont $75 \mathrm{p}$. Ioo des protéines étaient apportés par un concentrat protéique 
U'TILISATION DES PRO'TÉINES PAR LE VEAU

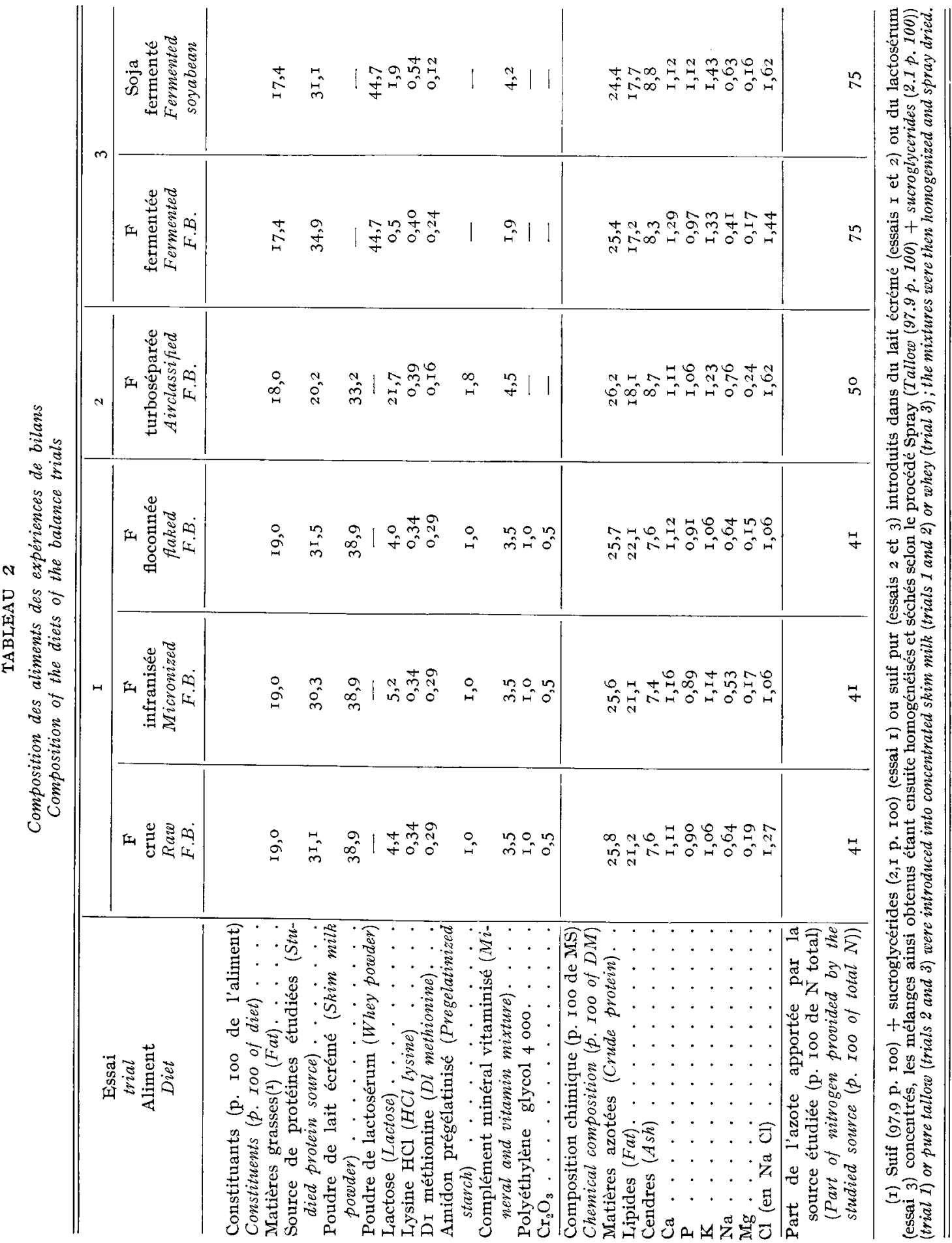


cru de fèves du Maroc préparé par turboséparation était très mal consommé, il a été décidé de limiter le taux de substitution des protéines du lait à 50 p. Ioo (tabl. 2).

Trois veaux mâles de race Frisonne ont été achetés à 1'âge d'environ 8 jours. Ils ont d'abord reçu pendant 36 jours le lait de remplacement classique auquel a été substitué en 4 jours l'aliment "Féverole turboséparée ". Les mesures ont commencé 2 jours après la fin de la transition et ont été effectuées en 4 périodes successives de 2 semaines.

\section{Essai 3: Utilisation digestive de la féverole et du soja fermentés}

Les 2 aliments expérimentaux étudiés étaient dépourvus de poudre de lait écrémé (tab1. 2); les produits fermentés apportaient 75 p. Ioo des protéines, le reste étant fourni par de la poudre de lactosérum et des acides aminés de synthèse.

Six veaux mâles de race Frisonne, achetés à l'âge d'environ 8 jours, ont d'abord reçu pendant 3 jours le lait de remplacement classique auquel ont été substitués en 4 jours les aliments expérimentaux. Chacun d'entre eux a été distribué aux 3 mêmes veaux jusqu'à la fin de l'essai. Les mesures ont commencé 2 jours après la fin de la transition et ont été effectuées en 5 périodes successives de 2 semaines.

\section{Rationnement}

Les animaux ont été pesés le premier jour de chaque période et le lendemain de la fin de la dernière période. Ils ont été nourris au seau 2 fois par jour. Les quantités d'aliment distribué au cours de chaque période étaient constantes et proportionnelles au poids métabolique des animaux $(57 \mathrm{~g}$ de matière sèche $/ \mathrm{j} / \mathrm{kg}$ poids vif ${ }^{0,75}$, sauf chez les veaux fistulisés de l'essai I et pendant la première période de 1'essai 3 , où elles ont été de $52 \mathrm{~g}$ ). Le poids métabolique était calculé d'après le poids vif en début de période, augmenté de $5 \mathrm{~kg}$.

\section{Prélèvements et échantillonnage}

Les méthodes de récolte et de préparation des échantillons de fèces et d'urine pour l'étude de la digestibilité et du bilan azoté ont été rapportées par GuilıoTEAU et al. (r977). Les acides aminés et les hexosamines des fèces des essais de bilans I et 2 ont été dosés sur des échantillons moyens correspondant à chaque régime, obtenus en mélangeant en quantités égales, les fèces lyophilisées des veaux recevant ce régime. Dans l'essai de bilans 3, 2 échantillons moyens correspondant respectivement aux périodes I et 5 , ont été obtenus selon le même principe pour chaque régime.

L'analyse de l'azote, des acides aminés et des hexosamines des digesta iléaux a porté sur des échantillons moyens des prélèvements effectués toutes les 6 heures, pendant 3 jours consécutifs; un échantillon a été préparé pour chaque veau en introduisant une partie aliquote des effluents recueillis à la canule dans un récipient maintenu à — I $5^{\circ} \mathrm{C}$ jusqu'à la lyophilisation. Dans le cas de l'aliment Féverole infranisée, l'échantillon moyen soumis à l'analyse a été constitué par le 
mélange en quantités égales de chacun des 2 échantillons moyens lyophilisés récoltés sur les 2 veaux qui consommaient cet aliment.

Les acides aminés libres du sang ont été dosés sur un échantillon moyen constitué par le mélange de volumes égaux du sang prélevé 4 heures après le repas du matin, le dernier jour des essais I et 3 , dans la veine jugulaire des veaux qui recevaient le même régime ( 2 dans l'essai $\mathbf{I}$ et 3 dans l'essai 3 ). Le mélange a été fait dans un flacon contenant de l'éthanol $95^{\circ}$ froid, additionné de $2 \mathrm{p}$. Ioo de thiodiglycol.

\section{Analyses et calculs}

Les acides aminés ont été dosés sur résine échangeuse d'ions, après hydrolyse acide (PRUGNAUd et PION, I976), dans le cas des aliments, des fèces et des digesta iléaux et après extraction éthanolique et purification sur résine échangeuse d'ions des extraits (PAWLAK et PION, I968), dans le cas des acides aminés libres du sang.

Les compositions en acides aminés des protéines ont été comıarées 2 à 2 en calculant la distance $\mathrm{d} \mathbf{u} \chi^{2}$ de la manière suivante :

$$
\chi^{2} \text { entre les protéines } i \text { et } j=\mathrm{I} 7 \sum_{k=\mathrm{x}}^{\mathrm{I}} \frac{(\mathrm{AA} i k-\mathrm{AA} j k)^{2}}{\frac{\mathrm{AA} i k+\mathrm{AA} j k}{2}}
$$

AA $i k$ et AAjk sont les pourcentages respectifs de l'acide aminé $k$ dans la somme des teneurs en acides aminés dosés (tabl. 5 et 7 ) dans les protéines $i$ et $j ; k$ représente les différents acides aminés et varie de I à $\mathbf{I} 7$. P1us la distance du $\chi^{2}$ est élevée et plus les protéines comparées sont différentes.

Les autres méthodes, concernant l'analyse des hexosamines, le dosage des glucides et celui des activités antitrypsique et hémagglutinante ont été décrites antérieurement respectivement par COMBE et al. (I980), CERNING-BEROARD (I977) et VALDEBOUZE et al. (I980).

\section{Expérience d'engraissement}

Le but de cet essai était d'étudier l'influence du remplacement d'une partie des protéines du lait par celles des féveroles crue, infranisée ou fermentée. Pour cela, 4 aliments d'allaitement ont été utilisés (tab1. 3). Dans l'aliment Témoin, les protéines provenaient exclusivement de la poudre de lait écrémé. Dans les 3 autres aliments, les féveroles étudiées apportaient I4 p. Ioo des protéines digestibles, le reste étant fourni par la poudre de lait écrémé et de la lysine et de la méthionine de synthèse. Ce faible taux de substitution a été choisi, compte tenu de l'appétit et la croissance médiocres observés lors du premier essai de bilans. Les taux de suif ont été calculés de manière à obtenir la même teneur en énergie digestible dans les 4 aliments.

Quarante-huit veaux mâles de race Frisonne ont été achetés à 1'âge d'environ 8 jours. A l'issue d'une période d'observation de 6 jours, au cours de laquelle ils ont reçu un lait de remplacement classique, ils ont été répartis en 4 lots de 2 animaux, compte tenu de leur poids vif, de leur gain de poids vif depuis l'arrivée, de la valeur de leur hématocrite et de leur état sanitaire. Les aliments expérimen-

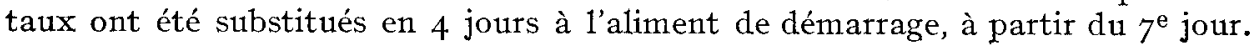


TABLEAU 3

Composition des aliments de l'expérience d'engraissement Composition of the diets of the fattening trial

\begin{tabular}{|c|c|c|c|c|}
\hline \multirow{2}{*}{$\underset{\text { Diet }}{\text { Aliment }}$} & \multirow{2}{*}{$\begin{array}{l}\text { Témoin } \\
\text { Control }\end{array}$} & \multicolumn{3}{|c|}{$\begin{array}{l}\text { Féverole } \\
\text { Field bean }\end{array}$} \\
\hline & & $\begin{array}{l}\text { Crue } \\
\text { Raw }\end{array}$ & $\begin{array}{l}\text { Infranisée } \\
\text { Micronized }\end{array}$ & $\begin{array}{l}\text { Fermentée } \\
\text { Fermented }\end{array}$ \\
\hline 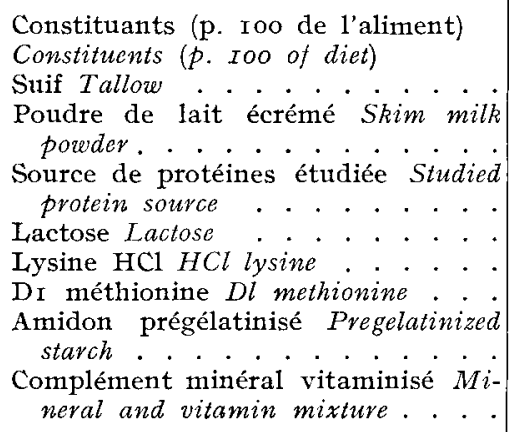 & $\begin{array}{c}18,0 \\
67,6 \\
- \\
10,75 \\
-\end{array}$ & $\begin{array}{l}21,4 \\
57,7 \\
15,0 \\
1,83 \\
0,12 \\
0,05 \\
1,2 \\
2,70\end{array}$ & $\begin{array}{l}57,7 \\
\text { I I,I } \\
7,53 \\
0, \mathrm{I} 2 \\
0,05 \\
\text { I,7 } \\
2,70\end{array}$ & $\begin{array}{r}18,8 \\
57,7 \\
6,8 \\
12,53 \\
0,09 \\
0,03 \\
1,7 \\
2,35\end{array}$ \\
\hline 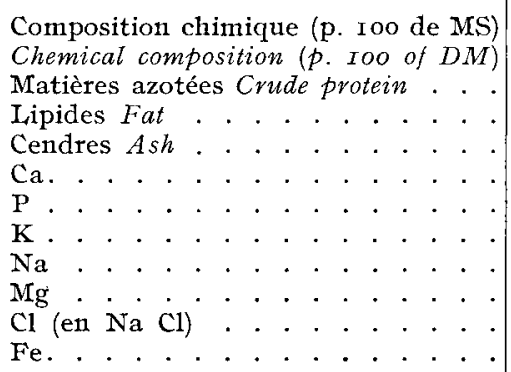 & $\begin{array}{c}24,2 \\
19,9 \\
7,2 \\
1,09 \\
1,07 \\
1,09 \\
0,46 \\
0,16 \\
1,27 \\
0,0012\end{array}$ & $\begin{array}{l}25,2 \\
22,7 \\
7, \mathrm{I} \\
\mathrm{I}, 08 \\
\mathrm{I}, 07 \\
\mathrm{I}, 04 \\
0,40 \\
0, \mathrm{I} 6 \\
\mathrm{I}, 04 \\
0,00 \mathrm{II}\end{array}$ & $\begin{array}{l}24,3 \\
20,7 \\
7,0 \\
1,09 \\
1,09 \\
1,09 \\
0,42 \\
0,19 \\
1,38 \\
0,0007\end{array}$ & $\begin{array}{l}24,0 \\
19,8 \\
7, \mathrm{I} \\
\mathrm{I}, 07 \\
\mathrm{I}, 00 \\
0,99 \\
0,37 \\
0,16 \\
\mathrm{I}, 06 \\
0,001 \mathrm{I}\end{array}$ \\
\hline
\end{tabular}

Les animaux ont été alimentés selon leur poids vif et leur appétit. La concentration est passée progressivement de Ioo à I90 $\mathrm{g}$ d'aliment d'allaitement par $\mathrm{kg}$ de lait de remplacement et la quantité de matière sèche distribuée de 580 à $28 \mathrm{ro} \mathrm{g} / \mathrm{j}$ au cours de la période expérimentale. Les aliments ont été distribués au seau, à raison de 2 repas par jour; le repas du dimanche soir a été supprimé à partir de la $4^{\mathrm{e}}$ semaine de présence.

Les animaux ont été pesés à leur arrivée, une fois par semaine à heure fixe et avant 1'abattage. Des prises de sang ont été effectuées dans la veine jugulaire 4,32 , 60 et 95 jours après 1'arrivée, pour la détermination de la valeur de l'hématocrite.

L'abattage des veaux a été effectué ro5 jours après 1'arrivée. La carcasse chaude, le foie et les dépôts adipeux périrénaux ont été pesés. La longueur de la carcasse a été mesurée et la couleur de la viande a été notée subjectivement. 


\section{Résultats}

\section{Expériences de bilans}

L'appétit des animaux (tabl. 4) n'est très satisfaisant qu'avec les aliments Féverole et Soja fermentés (essai 3). Les aliments Féveroles crue et floconnée sont particulièrement mal consommés (respectivement I9,5 et I4,0 p. Ioo de refus). La croissance et 1'efficacité alimentaire sont toujours médiocres; elles sont cependant meilleures avec les aliments Féverole floconnée et surtout Féverole infranisée qu'avec 1'aliment Féverole crue.

\section{Digestibilité}

La digestibilité ne varie pas notablement avec l'âge, sauf dans l'essai 3, oì elle augmente de la première à la seconde période de mesures et se stabilise ensuite. L es différences entre les valeurs de la première période et les valeurs moyennes des 4 autres périodes sont respectivement de 0,055 et 0 , I or pour l'azote des aliments Féverole et Soja fermentés. Pour pouvoir comparer les résultats des 3 essais, les valeurs rapportées dans le tableau 4 pour l'essai 3 ne concernent que les 4 dernières périodes.

Dans 1'essai I, la digestibilité apparente est généralement plus élevée pour les aliments contenant les féveroles traitées que pour 1'aliment Féverole crue, mais seule la différence observée pour l'azote entre les aliments Féveroles crue et infranisée est significative. Dans l'essai 2, les résultats concernant les 2 premières périodes ne sont pas utilisés pour l'un des veaux dont le maintien défectueux en cage n'a pas alors permis une collecte quantitative des fèces; la digestibilité de l'azote est très voisine de celle observée pour l'aliment Féverole crue mais celle des lipides est inférieure de $0, \mathbf{1} 68$. Dans l'essai 3, les différences entre régimes sont minimes mais la digestibilité de l'azote et surtout celle des lipides sont plus faibles pour les aliments Féverole et Soja fermentés que pour l'aliment Féverole crue : les différences concernant les lipides sont respectivement de 0,059 et o,o9I.

En admettant que la digestibilité des protéines du lait $(0,95$ d'après TouLLEC, et al., I978) et celle des protéines du lactosérum (0,94 d'après ToulıLE et al. I974) ne sont pas modifiées par la présence des protéines de féverole et de soja, les valeurs calculées pour la digestibilité apparente de l'azote des féveroles crue, infranisée, floconnée, turboséparée et fermentée, ainsi que pour l'azote du soja fermentés, ont respectivement de $0,718-0,830-0,787-0,784-0,795$ et 0,790 .

Le coefficient de rétention apparente de l'azote est plus élevé avec les aliments Féveroles infranisée et floconnée qu'avec l'aliment Féverole crue. Aucune différence n'est observée entre les veaux recevant les aliments Féverole et Soja fermentés.

\section{Composition en acides aminés et en hexosamines des digesta iléaux et des fèces}

La composition en acides aminés des digesta iléaux et des fèces varie relativement peu avec le régime alimentaire (tab1. 5) : ainsi, les distances du $\chi^{2}$ obtenues en comparant les digesta entre eux sont comprises entre 8 et 30 , les valeurs correspondantes pour les fèces étant de 6 et $4^{2}$ (tabl. 6). Dans l'essai 3 , les teneurs en 
R. TOULIEC ET COLI.

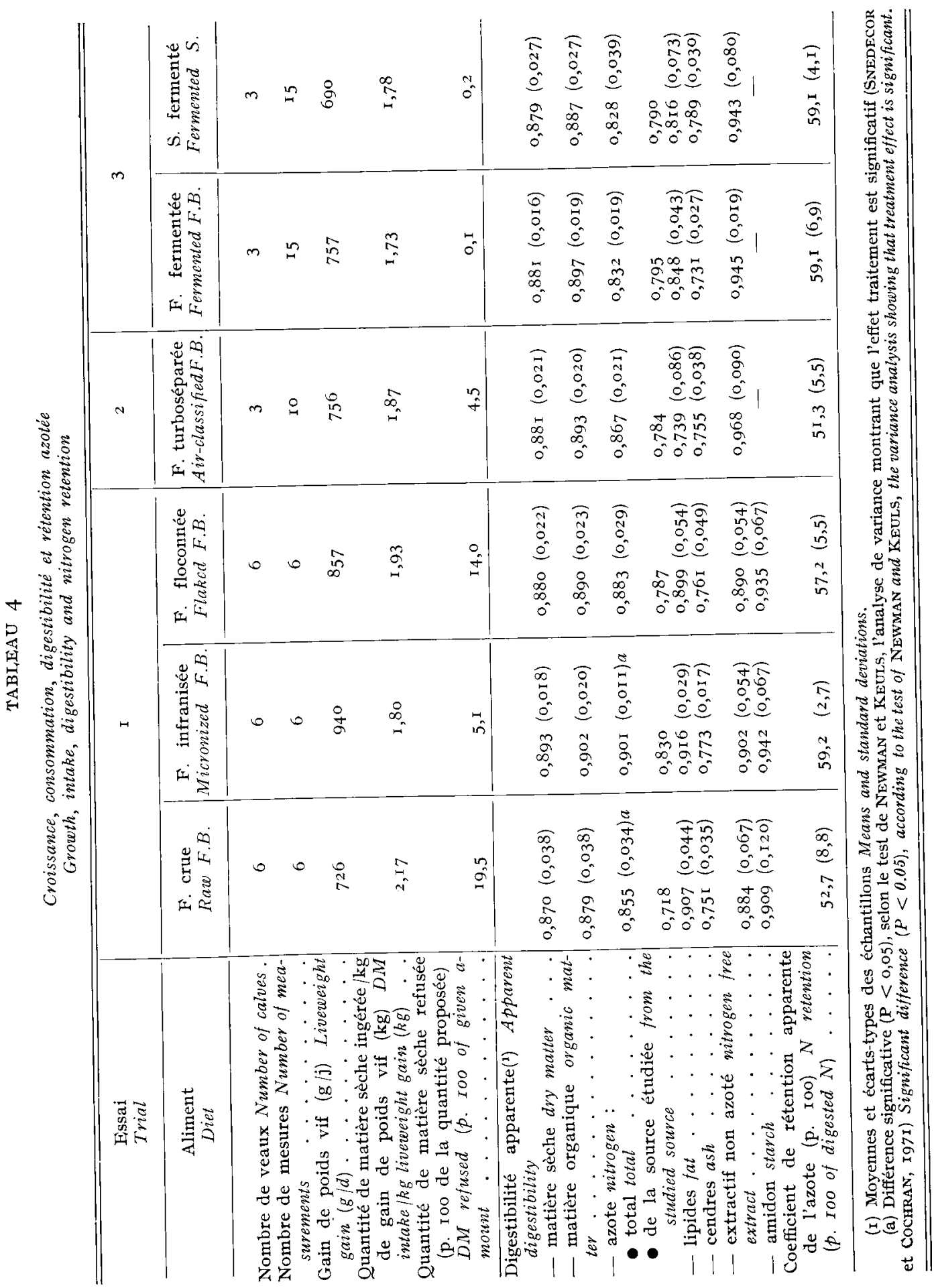




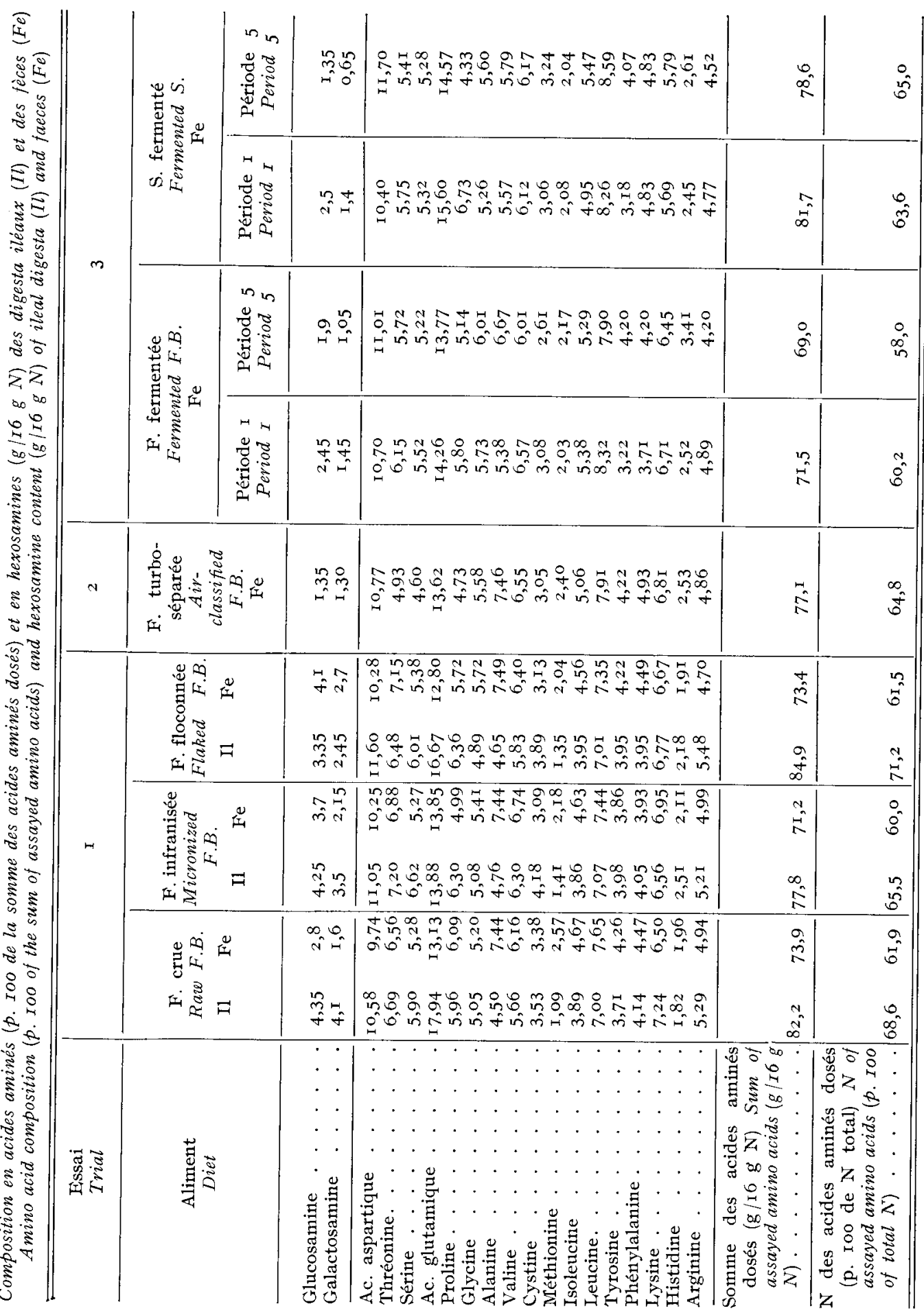


R. TOULIEC ET COLI.

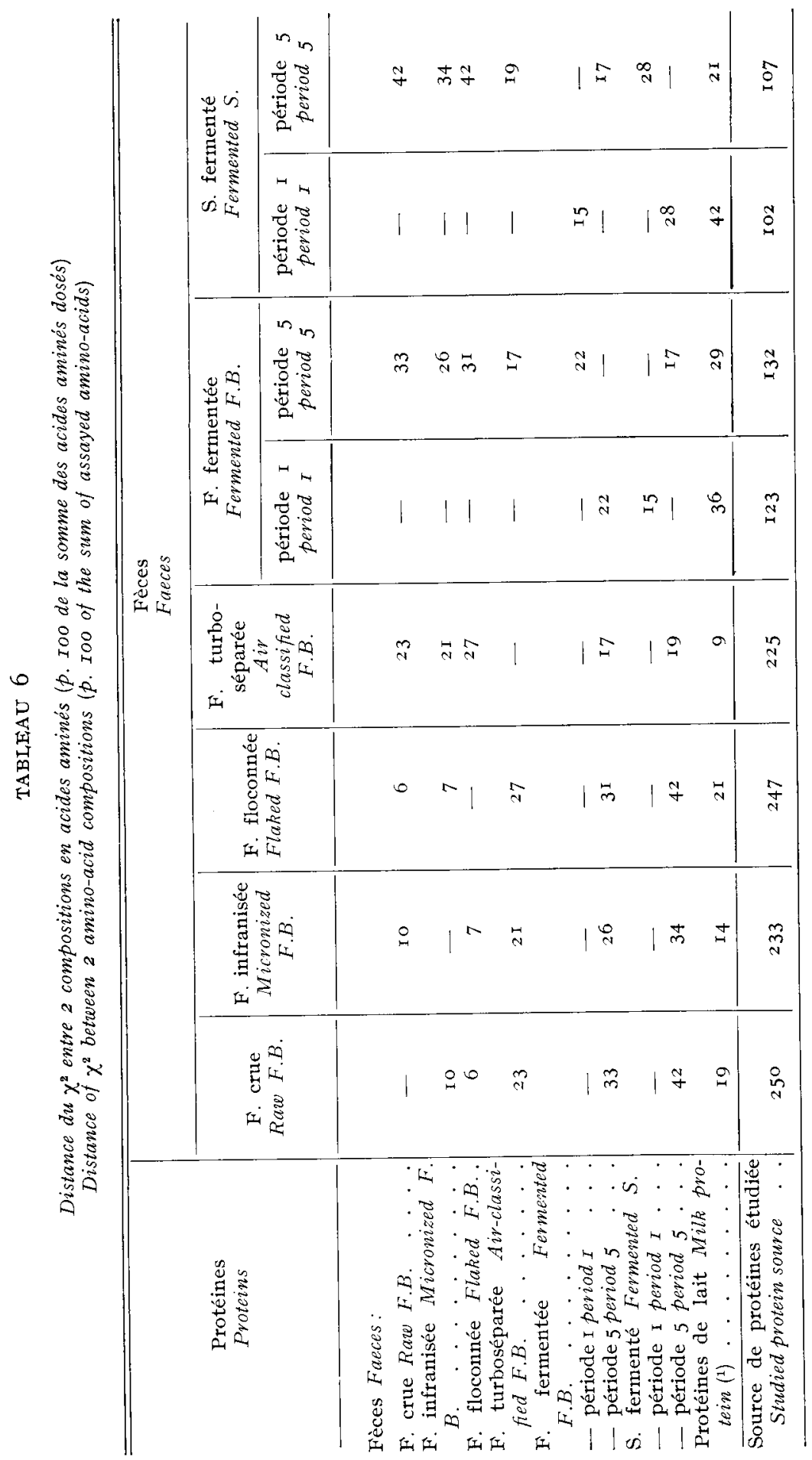




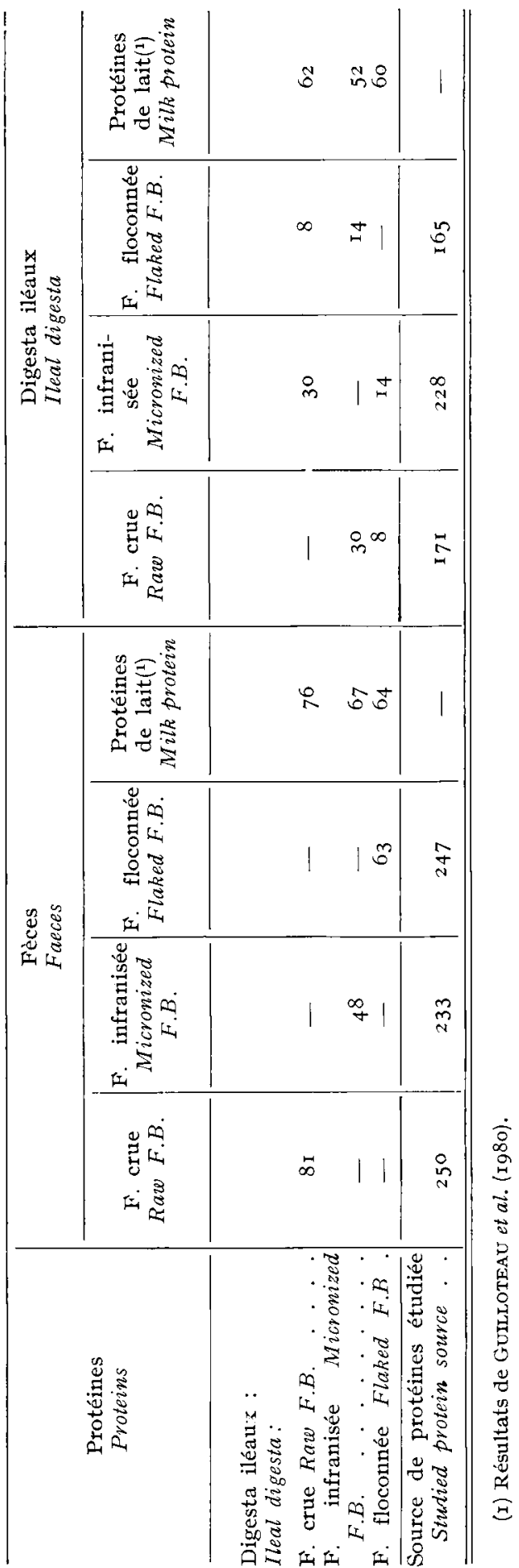


R. TOULLEC E'T COLI.

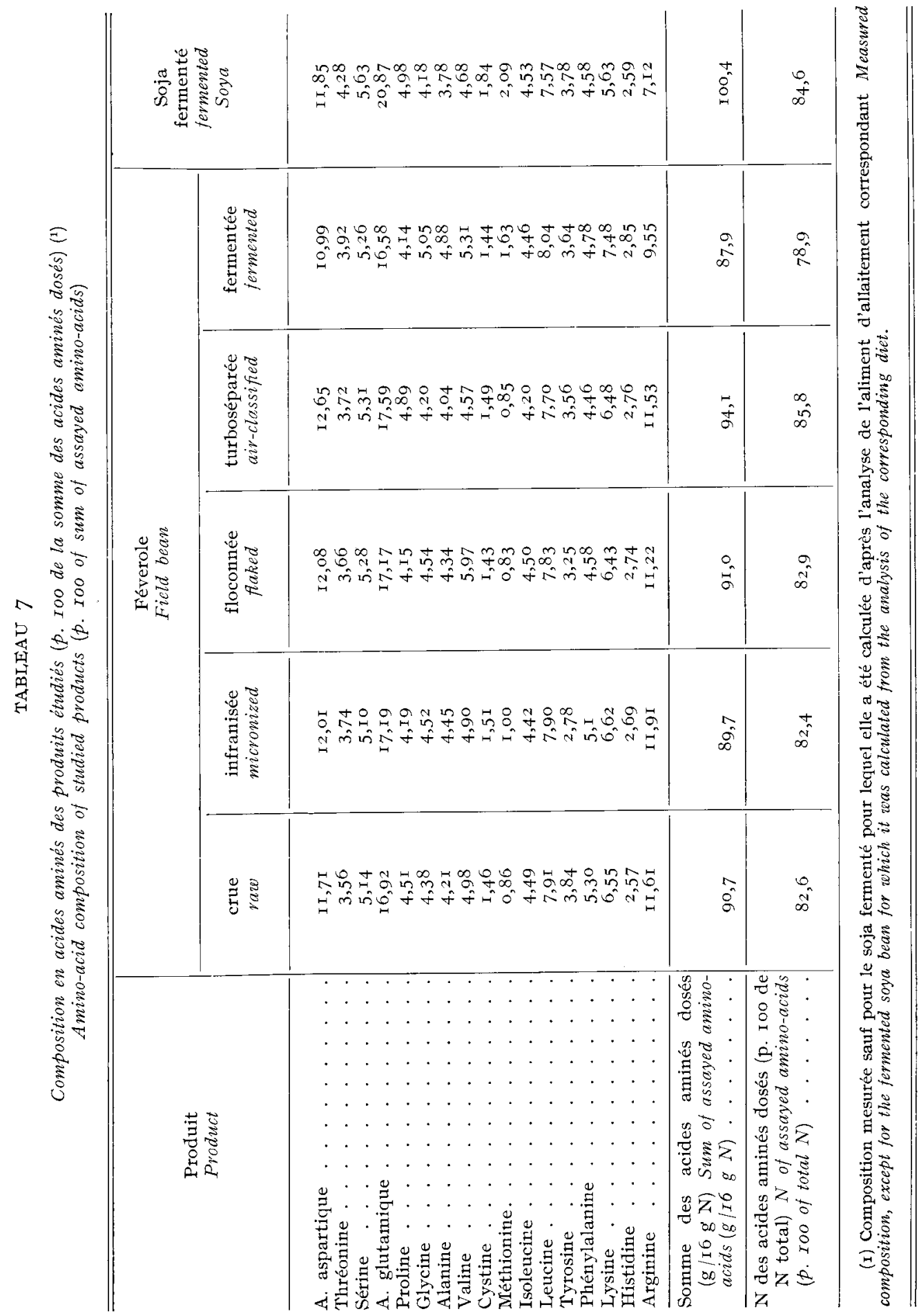


thréonine, en proline et surtout en hexosamines des fèces sont plus fortes en période I qu'en période 5; cependant, l'effet de l'âge sur la composition en acides aminés demeure très modéré puisque les distances $\mathrm{du} \chi^{2}$ entre les 2 périodes sont respectivement de 22 et 28 avec les aliments Féverole et Soja fermentés.

Les digesta iléaux sont plus riches en cystine et moins pourvus en alanine et en méthionine que les fèces des animaux recevant les mêmes aliments; les distances $\mathrm{d} u \chi^{2}$ entre les digesta iléaux et les fèces sont plus élevées ( 48 à $8 \mathrm{I}$ ) que celles observées en comparant les digesta ou les fèces entre eux. La part de l'azote sous forme d'acides aminés est plus importante dans les digesta iléaux que dans les fèces (tabl. 5). Les digesta iléaux sont plus riches en glucosamine et en galactosamine que les fèces, sauf avec le régime Féverole floconnée; dans tous les cas, le rapport galactosamine/glucosamine est plus élevé dans les digesta.

Les digesta iléaux et les fèces sont toujours plus riches en thréonine, glycine et cystine et moins pourvus en arginine que les produits étudiés (tab1. 5 et 7 ). Les distances $d u \chi^{2}$ entre les protéines des digesta iléaux ou des fèces et celles des produits étudiés sont très élevées (102 à 250) (tabl. 6).

\section{Teneurs en acides aminés libres du sang}

Les teneurs en acides aminés libres du sang sont peu différentes suivant le régime (tab1. 8). Avec les aliments Féveroles crue, infranisée et floconnée, les

TABLEAU 8

Teneurs en acides aminés libres et en urée du sang des veaux en bilans (mg p. too g de sang) Free amino acids and uvea blood levels in calves of balance trials ( $\mathrm{mg} / \mathrm{Ioo} g$ of blood)

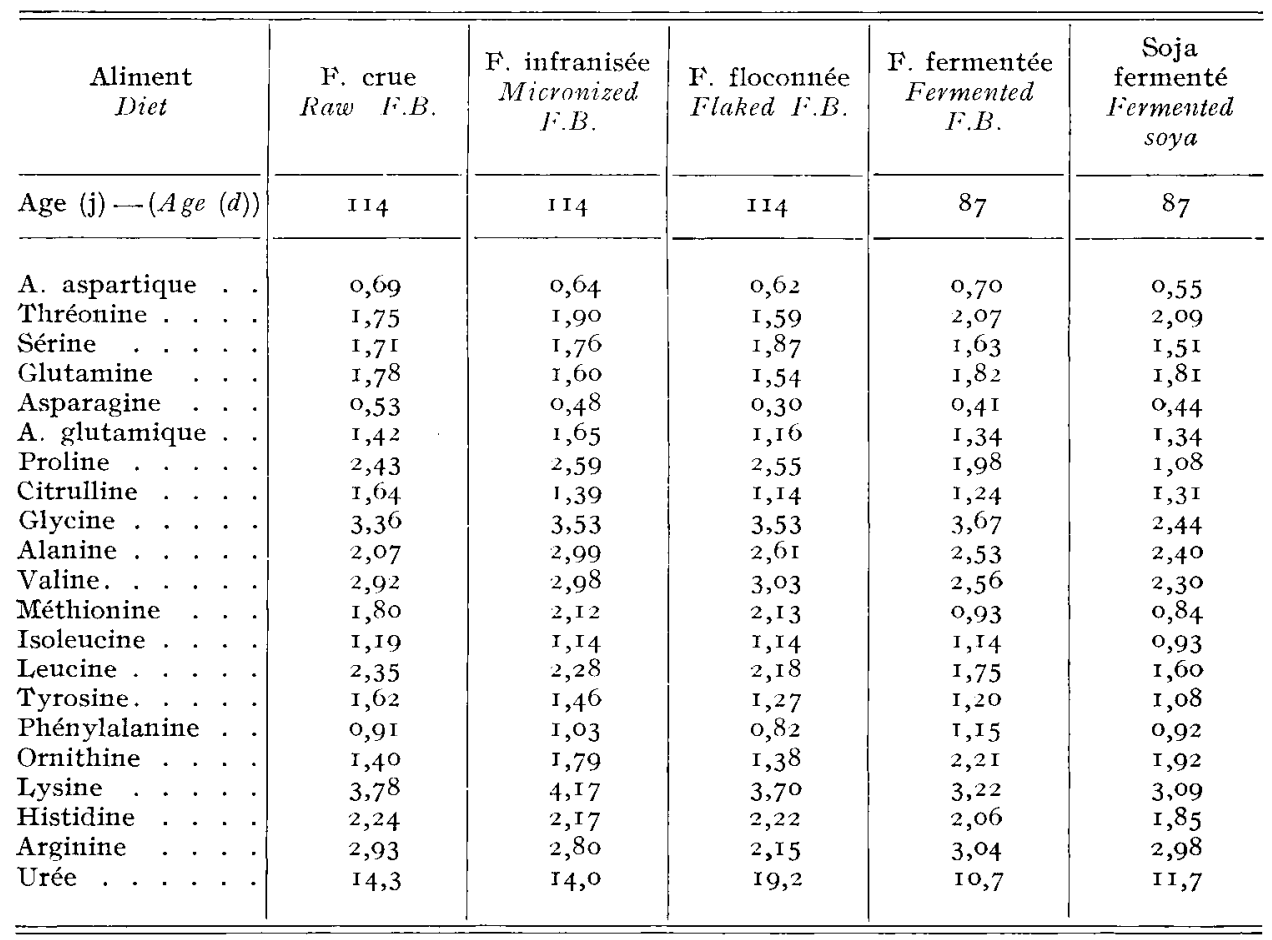


teneurs en thréonine sont plus faibles qu'avec les aliments Féverole et Soja fermentés; le contraire est observé pour la proline, la valine, la méthionine, la leucine, la tyrosine, la lysine et 1'histidine.

\section{TABLEAU 9}

Résultats de l'expérience d'engraissement

(moyennes et écarts-types des échantillons)

Results of the fattening trial (means and standard deviations)

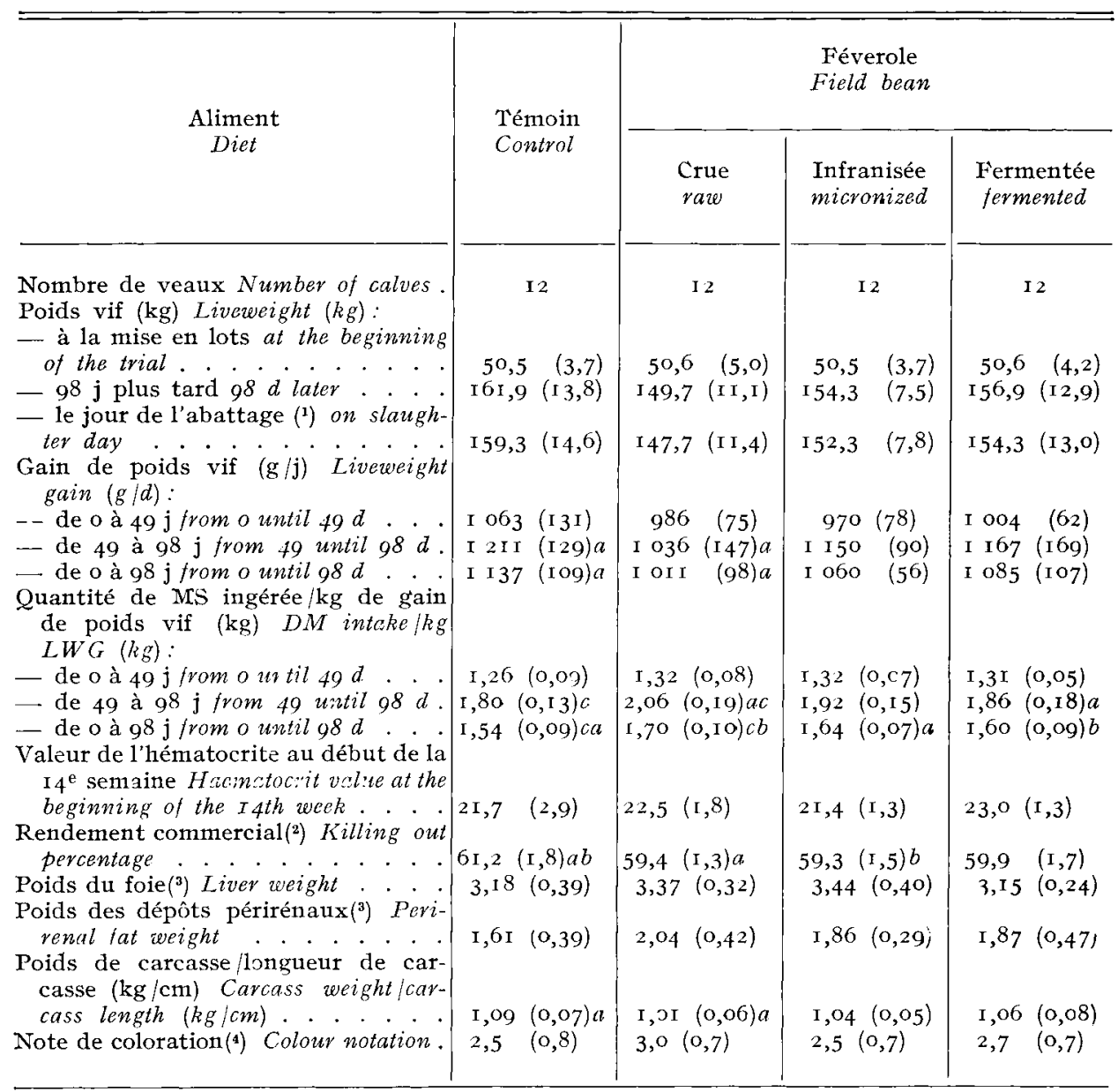

(I) $99 \mathrm{j}$ après la mise en lots, I7 h environ après le dernier repas (99 days after the beginning of the trial, about 17 h after the last meal.

(2) Poids de carcasse chaude en p. Ioo du poids vif (Warm carcass weight p. 100 of live-weight).

(3) En p. Ioo du poids de carcasse In p. 100 of carcass reeight.

(4) Notes de I (blanc) à 5 (rouge) Notation from 1 ( $w$ 'hite) to 5 (red).

$(a, b, c)$ : Les valeurs de la même ligne accompagnées des mêmes lettres sont significativement différentes $(a, b: \mathbf{P}<0,05-c: \mathbf{P}<0,0$ ) , selon le test de Newman et KevLs, appliqué quand l'analyse de variance montre que l'effet traitement est significatif Means with same superscripts are significantly different $(a, b: P<0.05-c: P<0.01)$, according to the text of NewMan and Keurs, applied when the variance analysis shows that treatment effect is significant). 


\section{Expérience d'engraissement (tab1.9)}

L'état sanitaire des animaux est toujours satisfaisant et n'est pas affecté par les traitements alimentaires. Les 4 aliments sont bien consommés puisque, pour l'ensemble de la période expérimentale, les quantités refusées par rapport aux quantités proposées ne sont que de I,5-2,4-0,9 et I,9 p. roo pour les animaux des lots Témoin et Féveroles crue, infranisée et fermentée, respectivement. Cependant, les refus se produisent principalement au cours des 3 dernières semaines avec les aliments Féveroles crue et fermentée.

Au cours des 7 premières semaines, les veaux recevant les régimes Féveroles réalisent des performances très voisines entre elles (tab1. 9) mais moins satisfaisantes que celles des animaux du lot Témoin (gain de poids vif inférieur de 5,6 à 8,7 p. IOo); cependant, les différences ne sont pas significatives. Au cours des 7 dernières semaines, les résultats obtenus avec les animaux du lot Féverole crue sont médiocres; ainsi, la quantité de matière sèche consommée par $\mathrm{kg}$ de gain de poids vif est plus élevée (respectivement de I4,4-7,3 et Io,8 p. Ioo) chez ces animaux que chez ceux des lots Témoin, Féverole infranisée et Féverole fermentée, mais seules la première et la dernière différences sont significatives. Les animaux des lots Féveroles infranisée et fermentée fournissent des résultats très voisins entre eux et non significativement inférieurs à ceux des veaux du lot Témoin.

Pour l'ensemble de l'essai, ce sont les performances des veaux du lot Féverole crue qui sont les moins satisfaisantes. Les différences concernant la croissance ne sont significatives que par rapport au lot Témoin; celles observées dans l'efficacité alimentaire le sont également par rapport au lot Féverole fermentée. Les performances des veaux des lots Féveroles infranisée et fermentée sont très voisines entre elles et inférieures (significativement pour l'efficacité alimentaire dans le cas du lot Féverole infranisée) à celles des veaux du lot Témoin.

A l'abattage, le rendement commercial des veaux des lots Féveroles crue, infranisée et fermentée est inférieur de I, $8(\mathrm{P}<0,05)-\mathrm{I}, 9(\mathrm{P}<0,05)$ et $\mathrm{I}, 3$ points à celui des veaux du lot Témoin. Le poids des dépôts adipeux périrénaux est plus élevé pour les animaux du lot Féverole crue, mais aucune des différences observées n'est significative. La conformation des carcasses, estimée d'après le rapport poids/longueur, est significativement inférieure pour les veaux du lot Féverole crue par rapport à ceux du lot Témoin. Les notes de coloration sont peu différentes. Les valeurs de l'hématocrite diminuent fortement avec l'âge chez les veaux des 4 lots; les différences observées Io jours avant 1'abattage, sont faibles et ne sont pas significatives.

\section{Discussion}

La digestibilité apparente de 1'azote de la féverole crue est faible $(0,72)$; elle est du même ordre de grandeur que celle obtenue dans notre laboratoire pour un tourteau de soja cuit $(0,74$ d'après PARUELLE et al., I972). Le floconnage, la turboséparation et la fermentation permettent d'accroître la digestibilité jusqu'à des valeurs $(0,78$ à 0,79$)$ voisines de celles observées pour le tourteau de soja fermenté $(0,79)$ et pour un tourteau de soja concentré par extraction hydroalcoolique du saccharose et des $\alpha$ galactosides (o,8o d'après Guir, LteAu et al., I977). Dans nos 


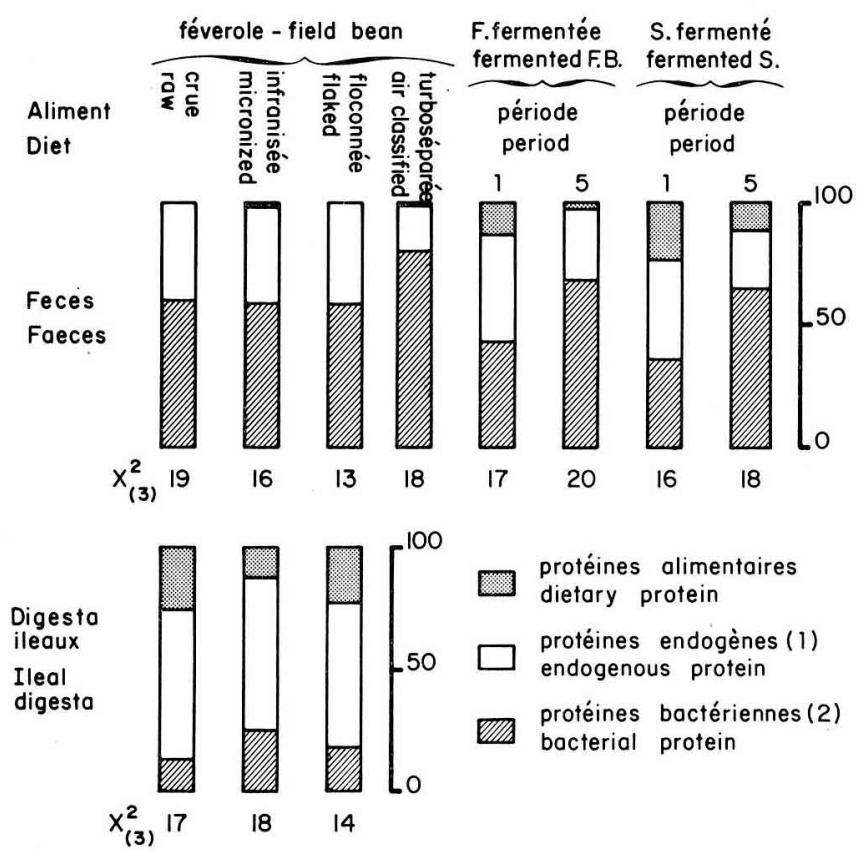

FIG. I. - Origine des protéines des digesta iléaux et des fèces des veaux (p. 100).

Origin of proteins (dictary, endogenous and bacterial) in ileal digesta and faeces of calves (p. 100)

(I) Composition en acides aminés de digesta iléaux de veaux nourris au lait (GUILLOTEAU et al., I980) Amino-acid composition of ileal digesta from milk fed calves.

(2) Composition en acides aminés des bactéries fécales de pores (MASON, JUST et BEch-ANDERSEN, 1976) A mino acid composition of bacteria isolated in pig faeces.

(3) Distance du $\chi^{2}$ entre la composition calculée du mélange et celle effectivement observée Distance of $\chi^{2}$ between the calculated composition of the mixture and that really observed.

conditions expérimentales, c'est l'infranisation qui a l'effet le plus favorable sur la digestibilité de l'azote qui atteint alors 0,83 ; cette valeur est très voisine de celles obtenues pour l'azote de concentrats protéiques de pomme de terre, de poisson de Norvège et de levures d'alcanes (respectivement $0,83-0,83$ et 0,84 d'après 'ToulLEC et COROLler, résultats non publiés; Guildoteted et al., I977; PARUEILE et al., I972). Cependant, la digestibilité de l'azote de la féverole infranisée demeure nettement inférieure à celle de l'azote de la poudre de lait écrémé, du lactosérum concentré par ultrafiltration, d'un hydrolysat de poissons blancs ou de bactéries cultivées sur méthanol (respectivement 0,95-0,94-0,9I et 0,9I d'après T'OULLEC et al., I978; TOUldec et al., I974; Paruelie et al., I974; Guilloteau, Toulied et Patureau-Mirand, i979).

Un effet favorable de l'infranisation et du floconnage sur la digestibilité de l'azote a également été observé chez le porcelet (SEVE, résultats non publiés). L'augmentation avec l'âge de la digestibilité de 1'azote obtenue dans 1'essai 3 est classique et correspond à une amélioration de l'efficacité de la digestion au cours du premier mois après la naissance (TERNOUTH et ROY, I973; TOULLEC et al., I974; WITTENBERG et INGALL S, I979). Les valeurs beaucoup plus faibles de la digestibilité des lipides dans les essais 2 et 3 pourraient être dues au fait que les aliments correspondants sont moins riches en lipides que ceux utilisés dans 1'essai I; mais cette explication est loin d'être suffisante. L'absence d'émulsifiants dans les ali- 
ments des essais 2 et 3 pourrait avoir un effet défavorable sur la digestibilité des lipides; cependant, cela paraît peu vraisemblable car l'addition du même mélange d'émulsifiants à un aliment contenant 25,5 p. Ioo de levures lactiques n'a eu aucun effet sur la digestibilité des lipides (TOUL $\mathrm{L}_{\mathbf{E}} \mathrm{C}$, résultats non publiés). Une autre cause serait l'absence de poudre de lait écrémé dans les aliments Féverole et Soja fermentés, mais cela n'est pas le cas pour l'aliment Féverole turboséparée, pour lequel la digestibilité des lipides est la plus basse. Il est possible également que les suifs incorporés dans les différents aliments n'aient pas tous des teneurs voisines en acide stéarique.

Si les compositions en acides aminés des digesta iléaux et des fèces sont très différentes de celles des aliments, elles sont en revanche beaucoup plus proches de celles des digesta et des fèces des veaux nourris au lait $\left(\chi^{2} \leqslant 62\right.$ pour les digesta et 36 pour les fèces) (tabl. 6). Cela indique que les protéines alimentaires ne sont pas en quantités très élevées dans les digesta iléaux et surtout dans les fèces, par rapport aux protéines endogènes ou bactériennes. Une illustration peut en être donnée en calculant le mélange de protéines alimentaires, endogènes et bactériennes dont la composition en acides aminés se rapproche le plus de celle des digesta iléaux ou des fèces $\left(\chi^{2}<20\right.$ ) (fig. I). L es protéines alimentaires sont assimilées à celles de ${ }^{1}$ a source étudiée puisque la digestibilité réelle des protéines du lait est très élevée. Les protéines de digesta iléaux de veaux nourris au lait sont utilisées pour représenter les protéines endogènes car elles ne comprennent que très peu de protéines alimentaires et microbiennes (GuILLOTEAU et al., I980). Les protéines de bactéries isolées de fèces de porcs (MASON, JUST et BECH-ANDERSEN, I976) sont choisies pour représenter les protéines microbiennes.

L'examen de la figure I indique que la faible proportion de protéines alimentaires dans les fèces des veaux de plus d'un mois résulte principalement de la digestion microbienne dans le gros intestin, au moins pour les aliments Féveroles crue, infranisée et floconnée, puisque les protéines alimentaires semblent se trouver en quantités non négligeables à la fin de 1'iléon. I, a part des protéines alimentaires paraît être plus faible à ce dernier niveau avec la féverole infranisée; l'augmentation de la digestibilité apparente de 1'azote de la féverole à la suite de l'infranisation serait donc due en partie à une amélioration de sa digestibilité réelle. Celle entraînée par le floconnage pourrait être surtout liée à une réduction de la quantité d'amidon qui échappe à la digestion dans 1'intestin grêle (BESLE, LASSAIAS et 'THIVEND, I980); elle n'aurait alors que peu d'intérêt pour l'animal car elle proviendrait d'une augmentation des quantités d'azote non protidique absorbé dans le gros intestin, consécutive à une moindre synthèse de protéines par les bactéries (ØRSKov et al., I970). Cet effet est peut être également important dans le cas de la turboséparation et de la fermentation qui permettent d'éliminer l'amidon soit seul (turboséparation), soit avec le saccharose et les $\alpha$ galactosides (fermientation). L'absence de données au niveau iléal ne permet pas cependant d'exclure une amélioration de la digestibilité réelle de 1'azote avec ces 2 derniers traitements.

La digestibilité apparente plus élevée de l'azote des aliments Féverole et Soja fermentés, au-delà de l'âge de 4 semaines, paraît correspondre en partie à une moindre excrétion de protéines d'origine alimentaire, du fait d'une digestion plus complète de ces protéines dans l'intestin grêle et/ou d'une digestion microbienne plus importante. Ainsi, chez le rat, la digestion microbienne permet d'améliorer la digestibilité apparente des matières azotées peu digestibles (COMBE et PION, I977).

Les teneurs en hexosamines des digesta iléaux sont relativement faibles avec les aliments Féveroles crue, infranisée ou floconnée, par rapport à celles obtenues 
par Combe et al. ( $\mathrm{Ig} 80$ ) chez des veaux nourris au lait $(5,8$ à $8,45 \mathrm{~g} / \mathrm{I} 6 \mathrm{~g} \mathrm{~N}$, au lieu de I4); cela confirmerait la part moins grande prise par les protéines endogènes avec les aliments Féveroles.

Les différences observées entre les aliments en ce qui concerne la composition en acides aminés, se retrouvent dans les teneurs en acides aminés libres du sang des veaux. Cela indique que la digestibilité des acides aminés n'est pas fortement affectée par le traitement technologique. Les teneurs sanguines ont des valeurs normales ou relativement élevées, compte tenu du niveau d'ingestion. Ce dernier point peut résulter d'une utilisation imparfaite de certains acides aminés. Cependant, il ne semble pas que cette utilisation incomplète soit due à une déficience ou à une indisponibilité en un acide aminé indispensable à l'exception du tryptophane qui n'est pas dosé. Ainsi, même dans le sang des veaux qui reçoivent les aliments Féveroles crue, infranisée et floconnée, les teneurs en thréonine sont normales, bien que les aliments paraissent déficients en cet acide aminé (PATUREAUMrrand et al., I974). Cela pourraît être dû̀ à une carence énergétique, compte tenu de la digestibilité peu élevée des aliments, mais cela semble peu probable puisque les teneurs en urée sont faibles et celles en acides aminés non indispensables (alanine notamment) relativement élevées. L'interprétation des différences d'amino-acidémie est cependant délicate, en l'absence de données sur la vitesse d'évacuation gastrique des aliments utilisés.

Dans l'expérience d'engraissement, la croissance et l'efficacité alimentaire moins satisfaisantes des animaux recevant l'aliment Féverole crue sont difficiles à expliquer, compte tenu du faible taux d'incorporation de la féverole. Il est peu probable que cet effet soit dù à un apport insuffisant de certains acides aminés indispensables car il ne s'estompe pas en finition, bien que la poudre de lait écrémé présente dans l'aliment Féverole crue apporte à elle seule assez de protéines (enviton $2 \mathrm{I}$ p. IOO) pour couvrir les besoins des veaux durant les 7 dernières semaines de 1'essai (TOULLEc et al., I978). L'activité antitrypsique relativement modérée de la féverole, n'est sans doute pas à mettre en cause. Il est donc possible que ce soient d'autres facteurs antinutritionnels (hémagglutinines, etc.), qui soient responsables de 1'effet dépressif de la féverole crue; ainsi, la formation d'anticorps contre les protéines alimentaires est souvent observée chez des veaux recevant des protéines de soja (VAN Adrichem et FrEns, I965; Smith et Sissons, I975; Barrat't, StrRachan et PorTer, I979; Kilshaw et Sissons, I979 $a$ et $b$ ) et les performances des animaux paraissent dans certains cas reliées au niveau d'anticorps circulants (VAN LEEUWEN, WEIDE et BRAAS, I969). L'influence défavcrable de la féverole crue augmente avec le temps puisque l'amélioration apportée par l'infranisation et la fermentation ne se manifeste qu'en finition; cela renforce 1'bypothèse de facteurs antinutritionnels agissant au niveau métabolique.

La diminution du rendement commercial avec la distribution des aliments contenant les produits issus de la féverole s'explique en partie par la détérioration de la conformation de la carcasse. Elle pourrait également être due à une augmentation du poids du tube digestif vide, non déterminée ici mais qui a été observée en remplaçant une partie des protéines du lait par celles du soja (Roy et al., I977). Cette augmentation était liée à un accroissement de l'épaisseur de la paroi des intestins qui a été attribuée notamment à une réaction d'allergie à l'égard des protéines alimentaires (Stobo et Rov, 1977; Barratt, Strachan et Porter, I 979). 


\section{Conclusion}

En définitive, la digestibilité apparente de l'azote de la féverole crue est faible; bien qu'elle puisse être améliorée par des traitements thermiques (floconnage et infranisation) ou fermentaires, les produits obtenus demeurent peu appétibles à l'exception de ceux ayant subi une fermentation. Le veau préruminant est très sensible à la qualité des protéines alimentaires puisque le remplacement d'une part très limitée des protéines du lait par celles de la féverole crue a des effets dépressifs sur les performances des animaux. L’infranisation et surtout la fermentation permettent de limiter ces effets, mais non de les supprimer. Aucun des traitements étudiés ne paraît fournir de produit susceptible d'apporter une part très importante des protéines des aliments d'allaitement pour veaux.

$$
\text { Accepté pour publication en septembre } 1980 \text {. }
$$

\section{Remerciements}

A la Délégation Générale à la Recherche Scientifique et Technique pour l'aide financière apportée à la réalisation de cette étude (contrat $n^{\circ}$ 74-7-1051);

aux Laboratoires A.R.I.A., 59, Quai de la Gare, 750r 3 Paris et à la Société URY, 63, Rue Drogon, $57009 \mathrm{Metz}$, qui ont préparé respectivement la féverole turboséparée et les produits fermentés; à M. Beste et P. ThIVLnd, du Laboratoire de la Digestion des Ruminants de 1'I.N.R.A. de Theix, qui ont dosé l'amidon dans les aliments et les fèces;

à G. BAyLE, đu Laboratoire d'F́tude du Métabolisme Azoté de 1'I.N.R.A. de Theix, qui a dosé les sucres aminés dans les digesta iléaux et les fèces.

\section{Summary}

\section{Infuence of technological processing on the utilization of field-bean proteins by preruminant calves}

The utilization of 5 products (table I) prepared from dehulled field-beans (raw, flaked, micronized field-beans or protein enriched either by air-classification or by fermentation with Saccharomyces carlbergensis) was studied in the preruminant calf.

Digestibility of milk replacers (Table 2 ) in which these products supplied $4 \mathrm{I}$ p. roo (raw, flaked and micronized field-beans), 50 p. Ioo (air-classified field-bean) or 75 p. Ioo (fermented field-bean) of the proteins, was measured in a series of balance trials. The rest of the proteins was supplied by whey powder (fermented field beans diet) or by skim-milk (other diets) and synthetic amino acids. Fermented field-bean was compared with soyabean meal fermented by the same yeast.

The appetite of the animals was only satisfactory with the field-bean and fermented soyabean diets (Table 4 ). The apparent digestibility of raw field bean nitrogen was low (0.72); flaking, air-classification and fermentation led to an increase of this digestibility in very similar proportions (until $0.79-0.78$ and 0.79 , respectively -beyond the age of I month), but the most favourable effect was obtained with micronization $(0.83)$. The digestibility of fermented soyabean (0.79) was the same as that of the corresponding field-bean.

Examination of the amino acid composition of the faeces revealed that they only contained a small proportion of dietary proteins (Table 5 and Fig. I); this was mainly due to the microbial digestion in the large intestine since rather non negligible amounts of dietary proteins were present in the distal part of the ileum, at least in the case of raw, flaked and micronized field-beans. The fraction of dietary proteins seemed to be smaller in that part of the intestine, with micronized 
field-bean. Thus, the increase in the apparent digestibility of field-bean nitrogen, caused by micronization seems at least partly to be due to an improvement of its true digestibility.

The effect of replacing a part of the milk proteins by those of raw, micronized or fermented field-beans, was studied during a fattening trial. Four milk replacers were used (Table 3 ). In the control diet, proteitis were exclusively supplied by skim milk powder. In the 3 other diets, the field-beans studied provided I 4 p. Ioo of the digestible proteins, the rest being supplied by skimmilk powder and synthetic amino acids. Each of these diets was offered to I 2 Friesian male calves between the ages of about ${ }_{1} 5$ and $i_{3}$ days.

Live weight gain, feed efficiency, and commercial dressing out were significantly lower with the raw field-bean diet than with the control diet (Table 9). Micronization and especially fermentation contributed to reducing but not to eliminating the alteration of growth and feed efficiency.

None of the processings studied seemed to give products liable to be used as a large protein fraction in milk replacers for preruminant calves.

\section{Références bibliographiques}

AdricheM (VAN) P. W. M., Frexs A. M., I965. Soyabean protein as alimentary antigen in fattening calves. Tijaschr. Diergeneesk., 90, 525-530.

BarratT M. E. J., Strachan P. J., PokTrk P., i979. Immunologically mediated nutritional disturbances associated with soya-protein antigens. Proc. Nutr. Soc., 38, I 43-I5o.

Besle M., LASSAlas Bernadette, Thivend P., I980. Digestion des glucides de la féverole par le veau préruminant. I. Utilisation dans le tube digestif. Reprod. Nuir. Dévelop., 20 (sous presie).

CERNING-BEROARD J., I977. Effect of technological processing on the carbohydrate composition of horse beans and on the susceptibility of starch to $\alpha$ anylase. In Protein quality from leguminosous crops. EUR $5686 \mathrm{EN}$, I25-I35.

Cerning J., SAPosnik A., Guilbo't A., 1975. Carbohydrate composition of horse beans (Vicia $f a b a)$ of different origin. Cereal Chemist., 52, I25-137.

Combe F., PATureau-Mirand P., BAyle G., Pion R., ig8o. Influence de l'aliment et de la microflore sur la teneur en sucres aminés des contenus digestifs et des fèces chez le veau préruminant, l'agneau ou le rat. Reprod. Nutr. Dévelop., 20, I 707-I 7 I5.

Comber E., PIox R., I977. Influence de l'axénie sur la composition en acides aminés des fèces chez le rat et l'agneau. Ann. Biol. anim. Bioch. Biophys., 14, 633-636.

Duthie I. F., Edwards D. G., Rogers B., Andrews R. J., Wright J. A., I974. Preliminary studies on the suitability of field bean (Vicia faba L) protein isolate for lambs and calves. Proc. Nutr. Soc., 33, 40 A-4I A.

Gullioteau P., Patureau-Mirand P., Toullec R, Prugnaud J., ig8o, Digestion des matières azotées du lait et des bactéries cultivées sur méthanol chez le veau préruminant. II. Composition en acides aminés des digesta iléaur et des fèces, teneurs en acides aminés libres du sang. Reprod. Nutr. Davelop., 20 (sous presse).

Guilioteau P., TOUlied R., Culioli J., LE Douaron D., I977. Utilisation des protéines par le veau préruminant à l'engrais. V. Utilisation digestive des protéines du poisson, du soja et de la féverole. Ann Zootech., 26, I5-28.

Guilioteau P., Toulleic R., Patureau-MLrand P., i979. Bilan de la digestion des protéines du lait et des bactéries cultivées sur méthanol à la fin de l'intestin grêle et du tube digestif du veau préruminant. Ann. Biol. anim. Bioch. Biophys., 19, 949-953.

KILshaw P. J., Sissons J. W., I979 a. Gastrointestinal allergy to soyabean protein in preruminant calves. Antibody production and digestive disturbances in calves fed with heated soyabean flour. Res. Vet. Sci., 27, $36 \mathrm{r}-365$.

KIrshaw P. J., Sissons J. W., r979 $b$. Gastrointestinal allergy to soyabean protein in preruminant calves. Allergenic constituents of soyabean products. Res, Vet. Sci., 27, 366-371.

LE DIVIDICH J., r973. Valeur protidique des graines de Vigna sinensis et de féverole: comparaison chez le rat avec le tourteau de soja. Ann. Zootech., 22, 267-277.

LEEUWEN (VAN) V. M., WEIDE H. J., BRAAS C. C., I969. Feeding value of soybean oil meal compared with dried skimmed milk. Versl. Landbowwk. Onderzoek. Ned., 732, I-I9.

MarquardT R. R., Mc Kirdy J. A., Ward T., CampbeiL L. D., i975. Amino-acid, hemagglutinin and trypsin inhibitor levels, and proximate analyses of faba beans (Vicia faba) and faba bean fractions. Can. J. Anim. Sci, 55, 42 I-429. 
Mason V. C., JUST A., Bech-ANDERsein S., 1976. Bacterial activity in the hindgut of pigs. 2. Its influence on the apparent digestibility of nitrogen and amino-acids. Z. Tierphysiol. Tievernuhr. Futtermittelk., 36, 310-324.

MELCiON J. P., VALdEBouze: P., I977. Effect of various industrial treatments on the antinutritionnal factors of field bean (Vicia faba L.). In Protein quality from leguminosous crops. EUR 5686 EN, II6-I24.

Ørskov E. R., Fraser C., Mason V. C., Mann S. O., I97o. Influence of starch digestion in the large intestine of sheep on caecal fermentation, caecal microflore and faecal nitrogen excretion. Brit. $J$, Nutr., 24, 67I-682.

Paruelife J. L., Toullac R., Frantzen J. F., Mathifu C.-M., i972. Utilisation des protéines par le veau préruminant à l'engrais. I. Utilisation digestive des protéines du soja et des levures d'alcanes incroporées dans les aliments d'allaitement. Ann. Zootech., 21, 3I8-33 I.

Paruelle J. L., Toullec R., Patureau-Mirand P., Mathifou C.-M., I974. Utilisation des protéines par le veau préruminant à l'engrais. II. Utilisation des protéines de poisson et influence de l'addition d'un complexant du fer. Ann. Zootech., 23, 519-535.

Patureau-Mirand P., Toulife R., Paruelle J. L., Prugnaud J., Pion R., i974. Influence de la nature des matières azotées des aliments d'allaitement sur l'amino-acidémie du veau préruminant. I. Matières azotées du lait, du lactosérum, du poisson et des levures d'alcanes. Ann. Zootech., 23, 343-358.

PaWlak M., Pion R., ig68. Influence de la supplémentation des protéines du blé par des doses croissantes de lysine sur la teneur en acides aminés libres du sang et du muscle du rat en croissance. Ani. Biol, anim. Bioch. Biophys., 10, 317-322.

Prugnaud J., Pion R., i976. Dosage des acides aininés dans les aliments. Journées de Biochimie Beckman. Nantes.

Roy J. H. B., Storo I. J. I., Shotton S. M., Gandirton P., Gili.les C. M., I977. The nutritive value of non-milk proteins for the preruminant calf. The effect of replacement of milk protein by soya-bean flour or fish-protein concentrate. Brit. I. Nutr., 38, I67-187.

SMith R. H., Sissons J. W., I975. The effect of different feeds, including soyabean products, on the passage of digesta from the abomasum of the preruminant calf. Brit. J. Nutr., 33, 329-349.

SNEDECOR G. W., COCHran W. G., I97I. Méthodes statistiques, $287-306$. Association de coordination technique agricole, Paris.

Stobo I. J. F., Roy J. H. B., I977. Use of non-milk protein in milk substitutes for calves. World Anim. Rev., 25, I8-24.

TANGUY J., Martis M., I973. "Communication personnelle ".

TERroinf E., i93 I. De l'emploi des laits artificiels datis l'élevage du bétail. Bull. Soc. Sci. Hyg. Alim. Al. Ration. Homme. 19, I-23.

TERNOUTH J. H., ROY J. H. B., I 973. Effect of diet and feeding technique on digestive function in the calf. Ann. Rech. Vét., 4, I9-30.

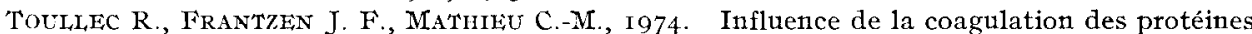
du lait sur l'utilisation digestive d'un lait de remplacement par le veau préruminant. Ann. Zootech., 23, 359-364.

Toumlec R., Frantzen J. F., Maubois J. L., Pion R., I974. Utilisation digestive, par le veau préruminant, des protéines du lactosérum traitées par ultrafiltration sur membrane. Techn. Laitiève, 828, I 7-2I.

TOULLEC R., THIVMND P., VERMorEL M., GUEGUEN L., I978. Veau préruminant. In I.N.R.A., Alimentation des ruminants, 245-274, I.N.R.A. publications, 78000 Versailles.

VAIDEBOUZE P., BitRGERON E., GABORIT T., DHLORT-LAVAL J., ig80. Content and distribution of trypsin inhibitors and hemagglutinins in some legume seeds. Can. J. Plant Sci., 60, 695-7or.

VERMOREL M., I 972. Influence du décorticage sur la valeur nutritive de la féverole. Premiers résultats obtenus chez le porc et le rat en croissance. Bull. Techn. C.R.Z.V., 11, I5-I8.

WI'TENBERG K. M., INGALLS J. R., I979. Utilization of fababean protein concentrate in milk substitute diets by preruminant calves. J. Dairy Sci., 62, I626-I63I. 